\title{
CLUBE DE CIÊNCIAS: UM OLHAR A PARTIR DAS TESES E DISSERTAÇÕES BRASILEIRAS
}

SCIENCE CLUB: A LOOK FROM BRAZILIAN THESES AND DISSERTATIONS

\author{
CLUB DE CIENCIA: UNA MIRADA DE TESIAS Y DISERTACIONES \\ BRASILEÑAS
}

\author{
Nilciane Pinto Ribeiro de Sousa* (iD) (9) \\ Rodney Haulien Oliveira Viana ${ }^{* *}$ (D) 9 \\ Gecilane Ferreira $^{* * *}$ (D) $(9$ \\ Leonardo Cipriano Nogueira $^{* * * *}$ (D)
}

\begin{abstract}
RESUMO
$\mathrm{O}$ ensino e a aprendizagem podem ocorrer em espaços formais e em espaços não formais de aprendizagem. O Clube de Ciências é uma proposta não formal de educação científica. A pesquisa objetivou analisar as teses e dissertações produzidas no Brasil nos últimos dez anos sobre Clube de Ciências, investigando a ocorrência, procedência e os principais enfoques dos objetivos desses estudos para, assim, realizar apontamentos acerca das produções científicas brasileiras sobre Clubes de Ciências. O presente estudo compreende uma pesquisa de abordagem qualitativa, realizada por meio de uma revisão bibliográfica de teses e dissertações disponíveis nos Bancos de Teses e Dissertações da CAPES e da BDTD durante o período de 2011 a 2020, cujos dados foram analisados por meio do método da Análise de Conteúdo de Bardin. Os resultados evidenciaram uma maior concentração de pesquisas nas regiões Norte e Sul do País, apresentando como principais participantes estudantes dos anos finais do Ensino Fundamental. A análise dos objetivos possibilitou a identificação de cinco categorias de acordo com a questão central de enfoque dos trabalhos, sendo elas: Promoção da Alfabetização Científica e construção do conhecimento científico dos alunos, Investigações sobre desenvolvimento dos Clubes de Ciências, Formação de professores, Contribuições na formação dos estudantes e Espaço para iniciação e divulgação científica. Concluímos que os Clubes de Ciências possuem grande relevância para o ensino de ciências, sendo uma importante ferramenta de
\end{abstract}

\footnotetext{
*Mestrado em Ensino de Ciências e Matemática (PPGecim-UFT). Professora da educação básica do Tocantins (SEDUC-TO), Araguaína, Tocantins, Brasil. Endereço para correspondência: Avenida Paraguai, s/n ${ }^{\circ}$, esquina com a Rua Uxiramas- Setor Cimba Araguaína, Tocantins, Brasil, CEP 77824-838. E-mail: nilcibio@hotmail.com

** Doutorado em Botânica (UFV). Professor do Programa de Pós-Graduação em Ensino de Ciências e Matemática (PPGecim-UFT), Araguaína, Tocantins, Brasil. Endereço para correspondência: Avenida Paraguai, s/n ${ }^{\circ}$, esquina com a Rua Uxiramas- Setor Cimba Araguaína, Tocantins, Brasil, CEP 77824-838. E-mail: rodney@mail.uft.edu.br

"In memoriam" Doutorado em Educação e Ensino de Ciências (REAMEC/UFMT). Professor do Programa de Pós-Graduação em Ensino de Ciências e Matemática (PPGecim-UFT), Araguaína, Tocantins, Brasil. . Endereço para correspondência: Avenida Paraguai, s/nº , esquina com a Rua Uxiramas- Setor Cimba Araguaína, Tocantins, Brasil, CEP 77824-838. E-mail: gecilaneferreira@uft.edu.br

${ }^{* * * *}$ Mestrado em Ensino de Ciências e Matemática (PPGecim-UFT). Professor da educação básica do Tocantins (SEDUC-TO), Araguaína, Tocantins, Brasil. Endereço para correspondência: Avenida Paraguai, $s / n^{\circ}$, esquina com a Rua Uxiramas- Setor Cimba Araguaína, Tocantins, Brasil, CEP 77824-838. E-mail: leonardobio93@gmail.com
} 
alfabetização científica dos estudantes, contribuindo, assim, para a formação pessoal e científica.

Palavras-chave: Alfabetização Científica. Ensino de ciências. Espaço não formal de aprendizagem.

\begin{abstract}
Teaching and learning can take place in formal spaces and in non-formal learning spaces. The Science Club is a non-formal proposal for science education. The research aimed to analyze the theses and dissertations produced in Brazil in the last ten years about Science Club, investigating the occurrence, origin and main focuses of the objectives of these studies, thus making notes about Brazilian scientific production about Science Clubs. This study comprises a qualitative approach research, carried out through a literature review of theses and dissertations available in the CAPES and BDTD Theses and Dissertations Banks during the period from 2011 to 2020, whose data were analyzed using the method of Bardin's Content Analysis. The results showed a greater concentration of research in the North and South regions of the country, with students from the final years of Elementary School as the main participants. The analysis of the objectives allowed the identification of five categories according to the central issue of focus of the works, namely: Promotion of Scientific Literacy and construction of scientific knowledge of students, Investigations on the development of Science Clubs, Teacher training, Contributions to training of students and Space for initiation and scientific dissemination. We conclude that Science Clubs have great relevance for the teaching of science, being an important scientific literacy tool for students, thus contributing to personal and scientific training.
\end{abstract}

Keywords: Scientific Literacy. Science teaching. Non-formal learning space.

\title{
RESUMEN
}

La enseñanza y el aprendizaje pueden tener lugar en espacios formales y en espacios de aprendizaje no formales. El Club de Ciencias es una propuesta no formal para la educación científica. La investigación tuvo como objetivo analizar las tesis y disertaciones producidas en Brasil en los últimos diez años sobre Club de Ciencias, investigando la ocurrencia, origen y principales focos de los objetivos de estos estudios, tomando notas sobre la producción científica brasileña sobre Clubes de Ciencias. Este estudio comprende una investigación de enfoque cualitativo, realizada a través de una revisión de la literatura de las tesis y disertaciones disponibles en los Bancos de Tesis y Disertaciones CAPES y BDTD durante el período 2011 a 2020, cuyos datos fueron analizados mediante el método de Análisis de Contenido de Bardin. Los resultados mostraron una mayor concentración de la investigación en las regiones Norte y Sur del país, siendo los estudiantes de los últimos años de Educación Primaria los principales participantes. El análisis de los objetivos permitió identificar cinco categorías según el tema central de enfoque de los trabajos, a saber: Fomento de la Alfabetización Científica y construcción del conocimiento científico de los estudiantes, Investigaciones sobre el desarrollo de Clubes de Ciencias, Formación del profesorado, Aportes a la formación de alumnos y Espacio de iniciación y divulgación científica. Concluimos que los Clubes de Ciencias tienen una gran relevancia para la enseñanza de las ciencias, siendo una importante herramienta de alfabetización científica para los estudiantes, contribuyendo así a la formación personal y científica.

Palabras clave: Alfabetización Científica. Enseñanza de las ciencias. Espacio de aprendizaje no formal. 


\section{INTRODUÇÃO}

Estratégias de ensino diversificadas vêm sendo discutidas e aplicadas na busca de aprofundar e aprimorar o conhecimento dos alunos nas áreas das ciências da natureza, resolvendo situações-problema e estimulando o interesse pela ciência e pela pesquisa. Os Clubes de Ciências buscam ampliar o espaço para o desenvolvimento da curiosidade científica em sua dimensão histórica, social e cultural, considerando os questionamentos que surgem das experiências, expectativas e estudos teóricos dos alunos. Além disso, caracterizase como um espaço rico de possibilidades e de acesso ao conhecimento.

A formação de Clubes de Ciências é uma ferramenta para a inserção científica dos estudantes de forma mais criativa e dinâmica, proporcionando aos alunos uma aproximação e experiência, no qual os próprios contextualizam e constroem o conhecimento científico. Tal oportunidade traz uma aproximação dos estudantes com a pesquisa logo no início de sua formação, desenvolvendo competências e habilidades que possibilitam a estes serem cada vez mais criativos, idealizadores e inovadores.

A pesquisa de trabalhos científicos constitui uma etapa fundamental para que se possa conhecer o que já foi produzido relacionado à temática de interesse. No Brasil, o tema "Clube de Ciências" vem sendo discutido desde sua implantação na década de 1950. Temos atualmente, espalhados pelo País uma grande quantidade de Clubes de Ciências. Desse modo, os locais e contextos diferenciados acabam refletindo na atuação e objetivos desses espaços não formais de ensino-aprendizagem. Assim, esta revisão busca elucidar o cenário atual das produções sobre a temática. Tendo em vista que grande parte das pesquisas publicadas procede dos estudos realizados nos Programas de Pós-Graduação das Universidades, esta revisão busca conhecer e refletir sobre o panorama atual brasileiro das produções científicas realizadas no meio acadêmico.

Nessa perspectiva, esta pesquisa foi orientada pelo seguinte questionamento: de que forma os Clubes de Ciências são abordados nas teses e dissertações realizadas no Brasil nos últimos 10 anos? Desse modo, estabelecemos como objetivo central da pesquisa: analisar as teses e dissertações produzidas no Brasil nos últimos dez anos sobre Clube de Ciências, investigando a ocorrência, procedência e os principais enfoques dos objetivos desses estudos, para, assim, realizarmos apontamentos acerca das produções científicas brasileiras sobre Clubes de Ciências.

Esta pesquisa torna-se relevante porque proporciona o mapeamento da última década 
de produção acadêmica no nível de mestrado e doutorado sobre os Clubes de Ciências. Além disso, ela pode ser útil aos professores de Ciências, incentivando a criação de novos Clubes de Ciências nas escolas e potencializando suas práticas de ensino.

\section{ESPAÇOS NÃO FORMAIS DE APRENDIZAGEM}

A educação entendida como formal é aquela que acontece nas instituições oficiais de ensino que possuem atividades associadas a um currículo pré-existente e organização própria e com regulamentação e legislação predefinidas (GADOTTI, 2000). Gohn (2014, p. 40) define a Educação formal como "aquela desenvolvida nas escolas, com conteúdos previamente demarcados".

Conforme Gohn (2014), a educação é não formal quando as práticas de aprendizagem são alicerçadas nos princípios da coletividade, da participação e da reflexão, comumente fora da escola, agindo como "um mecanismo complementar, onde o aluno obteria um aprofundamento ou um panorama complementar daquilo que aprendeu na escola" (GOHN, 2014, p. 42).

Conforme Fullan (1999), um ambiente de aprendizagem se caracteriza pelo trabalho colaborativo, que tenha uma ação planejada, em que ocorre a troca de informações, a investigação, a pesquisa e a exploração. Portanto, não há mais espaço exclusivo para o ambiente tradicional de aprendizagem, em que o trabalho é isolado, passivo e individualizado. Assim, a educação não deve ser entendida e desenvolvida somente em um local limitado, em um espaço formal ou em um momento específico de aquisição de conhecimentos, mas, sim, encarada como uma ação desenvolvida no cotidiano de forma contextualizada.

Os espaços não formais apresentam um modo particular de olhar a relação do ensino e aprendizagem, educando-educador bem como da construção do conhecimento. Os espaços não formais se constituem como ferramentas educacionais que buscam a aprendizagem, a educação dos sujeitos, a assimilação e a construção do conhecimento (BIANCONI; CARUSO, 2005).

Abreu (2001) aponta que a formação do indivíduo em seus aspectos básicofundamentais e na sua formação científica não deve ficar restrita apenas ao espaço escolar. Dessa forma, é necessário buscar outros espaços complementares ou alternativos, como museus, centros de ciências, Clubes de Ciências, que contribuam para estimular, ampliar, promover a inclusão e, o acesso ao conhecimento científico. Neste sentido, o ensino e a 
aprendizagem podem ocorrer dentro ou fora de uma sala de aula, em espaços formais e não formais. O Clube de Ciências é uma proposta não formal de educação científica (MENEGASSI et al., 2010).

Sem a pressão do ensino formal, realizar atividades orientadas nos Clubes de Ciências torna mais fácil para o estudante compreender conceitos e suas relações, além de vivenciar métodos de investigação, em contraposição ao ensino mecânico destituído de significado (SILVA; BORGES, 2009). Nessa perspectiva, os espaços não formais possuem uma prática intencional de ensino e da produção de saberes, que ocorre sem a rigidez da sala de aula, em diferentes espaços e de forma planejada, com o intuito de facilitar a aprendizagem (MARQUES; MARANDINO, 2018).

Um ambiente escolar de estudo e de debate científico, distante da rigidez da maioria das salas de aulas é de extrema importância, pois a ampliação do conhecimento científico é uma ferramenta imprescindível à participação política e cidadã. A criação e implementação de Clubes de Ciências vem acrescentar às possibilidades estudantis, apresentando-se como importante espaço onde as atividades são realizadas em horários de contraturno, sendo voltadas ao estudo, ao desenvolvimento de projetos e diálogos sobre temas que envolvem as ciências (SILVA et al., 2008).

\section{CLUBES DE CIÊNCIAS NO BRASIL}

A partir dos anos finais da década de 1950, com as mudanças advindas no ensino de ciências, reflexo do contexto político e econômico, nascem também os primeiros Clubes de Ciências no Brasil, que apresentavam como objetivo favorecer a vivência do método científico e incentivar a reprodução do que era realizado pelos cientistas em seus laboratórios de pesquisa. Uma concepção fortemente ligada ao contexto histórico marcado pelos avanços tecnológicos (MANCUSO; LIMA; BANDEIRA, 1996).

Após a década de 1970, o cenário educacional mudou. O destaque passou a ser uma abordagem dos conteúdos de forma não tradicional, que se aproxima da realidade e do cotidiano dos estudantes, buscando uma formação científica contextualizada. O ensino de ciências, desde então, tem passado por intensas modificações ao longo do tempo, envolvendo análises e pesquisas com alunos e professores, propondo novas metodologias, discutindo aspectos como motivação, interesse, linguagem e produção de materiais (KRASILCHIK, 1987). Diante de tantas mudanças no cenário educacional, os Clubes de Ciências têm 
buscado, no contexto da educação, romper com a forma tradicional de organização do tempo e dos espaços destinados convencionalmente pelas escolas para o ensino-aprendizagem das ciências da natureza (MANCUSO; LIMA; BANDEIRA, 1996; TOMIO; HERMANN, 2019).

Os primeiros Clubes de Ciências enfrentaram grandes desafios, pois mudar os padrões de ensino que sempre foram usados não era uma tarefa fácil (MANCUSO; LIMA; BANDEIRA, 1996). Porém, na medida em que foram sendo criados e desenvolvidos dentro das escolas, os Clubes demonstravam seu potencial e conquistavam credibilidade e confiança dos estudantes e da comunidade, principalmente dos pais e professores da escola. Mostravam que, como proposta, poderiam oferecer um conjunto de experiências mais significativas na vida dos estudantes, fornecendo o que as aulas de ciências na sala de aula, não conseguiam proporcionar, devido a fatores como o número insuficiente de aulas disponíveis para a disciplina durante a semana e o elevado número de estudantes em sala de aula.

Atualmente a concepção de Clube de Ciências foi ampliada, antes visava atender os avanços tecnológicos, agora tem a finalidade de tornar o ensino de ciências significativo, dar sentido à ciência pela conexão entre teoria e prática, utilizando processos de investigação contextualizados, que valorizem o cotidiano de realidades locais e regionais e ressaltem a interação do conteúdo científico com a dimensão social (RAMALHO, 2011).

Vários autores definem e interpretam o que vem a ser um Clube de Ciências. Conforme Bazo e Santiago (1981), o Clube, é constituído por uma associação de estudantes, orientados por professores, que realizam atividades educacionais, iniciação e divulgação científica, com a finalidade de despertar e desenvolver o interesse pela ciência.

Na concepção de Costa (1988) o Clube de Ciências é um espaço onde todos podem trocar ideias e realizar leituras e pesquisas dentro da própria comunidade. Possibilitando aos estudantes um maior envolvimento, uma vez que estes questionam, duvidam e buscam um resultado. Enquanto Gomes (1988) aponta que o Clube de Ciências é um local em que o processo ensino-aprendizagem se desenvolve interligado a um importante processo formativo e educativo, ocorrendo de modo espontâneo.

Nesse sentindo, entendemos que a definição de Clube de Ciências pode variar de acordo com a concepção de cada autor, porém não difere quanto a ser um espaço para encontros ou reuniões que buscam aprimorar o conhecimento no campo das ciências. Nessa perspectiva, os Clubes de Ciências possuem desafios importantes relacionados com o desenvolvimento pessoal e social dos estudantes, buscando, então, contribuir com a melhoria da educação, além de esclarecer e desmistificar o papel que a ciência possui perante a 
sociedade. Desse modo, apontamos que o ensino de ciências vem sendo essencial para o desenvolvimento das pessoas, não apenas dentro das salas de aula (BRASIL, 2006).

O Clube de Ciências desenvolve atividades que tem por finalidade oferecer aos alunos condições de observar, pensar, refletir criticamente, sobre questões da atualidade (SOUSA; CORRÊA; TUTTMAN, 2003) e, dessa forma, assumir um importante posicionamento perante elas. Os Clubes de Ciências também visam promover a participação dos alunos em feiras de ciências (espaços de divulgação científica dos saberes construídos e interação com demais estudantes e comunidades escolares), contribuindo, assim, para a formação integral dos alunos.

Segundo Souza e Dias (2011), o Clube de Ciências apresenta-se como um ambiente alternativo capaz de promover a popularização da ciência, podendo incentivar a interação entre professores e estudantes. Os clubes buscam compreender as teorias estudadas por meio de experimentos, aprofundar as leituras, interpretação e discussões, estimulando o aprendizado por meio da interação entre os participantes. Os Clubes de Ciências contribuem para que os alunos se tornem protagonistas do seu aprendizado nos aspectos cognitivos e nas relações sociais; rompendo, dessa forma, com o paradigma de que o professor é o único detentor do conhecimento, dando, assim, espaço para o aluno que pesquisa e que busca respostas aos seus questionamentos (SOUZA; DIAS, 2011).

\section{CAMINHOS METODOLÓGICOS}

O presente estudo compreende uma pesquisa de abordagem qualitativa. De uma maneira geral, a pesquisa de caráter qualitativo assume diferentes significados no campo das ciências sociais, compreendendo um conjunto de diferentes técnicas interpretativas que visam descrever e decodificar os componentes de um sistema complexo de significados (NEVES, 1996).

Esta pesquisa consiste em uma revisão bibliográfica, de caráter exploratório. Segundo Gil (1999, p. 43), “[...] as pesquisas exploratórias são desenvolvidas com o objetivo de proporcionar visão geral, do tipo aproximativa, acerca de determinado fato". A pesquisa bibliográfica é uma das mais importantes fontes de pesquisa, constituindo parte do processo inicial da investigação de qualquer tema (FERNANDES; GOMES, 2003).

Para a presente pesquisa, realizou-se uma revisão bibliográfica a partir do levantamento das teses e dissertações relacionadas ao tema Clube de Ciências, que foram 
produzidas no Brasil nos últimos dez anos. As buscas pelas produções científicas foram realizadas no Banco de Teses e Dissertações da Coordenação de Aperfeiçoamento de Pessoal de Nível Superior (CAPES) e na Biblioteca Digital de Teses e Dissertações (BDTD Brasileira). As dissertações e teses foram selecionadas a partir dos seus títulos, utilizando como descritor o tema "Clube(s) de Ciência(s)", no período compreendido entre 2011 a 2020. Foram encontradas 40 dissertações e 5 teses no banco da CAPES e 21 dissertações e 3 teses na BDTD.

Após uma análise preliminar de cada trabalho, algumas produções foram retiradas do estudo, por não corresponderem ao objeto de estudo analisado. Dessa forma, após a filtragem, a revisão foi realizada utilizando 35 produções (dissertação/tese). O corpus da análise foi desenvolvido com base na investigação dos resumos das dissertações encontradas. Nos casos em que os resumos não foram suficientes para um panorama geral da pesquisa, as informações foram buscadas ao longo dos textos das dissertações e teses.

As informações obtidas foram analisadas por meio da técnica denominada: Análise de Conteúdo. Bardin (2011) indica que a utilização da análise de conteúdo apresenta três fases fundamentais: pré-análise, exploração do material e tratamento dos resultados. Segundo Franco (2008), a pré-análise corresponde à organização, ao conjunto de buscas iniciais de intuições, primeiros contatos com os materiais, a escolha dos documentos e elaboração de indicadores que fundamentem a interpretação final. Nesta pesquisa, a pré-análise ocorreu com a busca e seleção das dissertações e teses nos bancos de dados por meio da filtragem do material de acordo com a temática do estudo.

$\mathrm{Na}$ fase de exploração do material, o corpus da pesquisa passa por um estudo mais aprofundado, os procedimentos, como codificação e a categorização, são realizados nessa fase da análise, surgindo, assim, os quadros de referências, buscando composições coincidentes e divergentes de ideias (TRIVINOS, 2009). Nesse sentido, essa fase foi realizada por meio das leituras e preenchimento das fichas para análises; em seguida, foi realizada a codificação das produções e a análise mais aprofundada dos trabalhos. Nessa fase, emergiram três categorias que buscam responder à questão de pesquisa deste estudo, a saber: 1) Distribuição das pesquisas sobre Clube de Ciências no Brasil; 2) Participantes das pesquisas sobre Clube de Ciências; e 3) Objetivos de investigação das pesquisas.

$\mathrm{Na}$ fase do tratamento dos resultados, o pesquisador, apoiado nos resultados brutos, procura torná-los significativos e válidos, sendo a fase de análise propriamente dita. Nessa 
fase, realizou-se o tratamento dos resultados obtidos por meio da interpretação e realização das inferências presentes no estudo.

\section{ANÁLISE E RESULTADOS}

\subsection{Distribuição das pesquisas sobre Clube de Ciências no Brasil}

Com relação ao período analisado, foram encontradas 32 dissertações e 3 teses distribuídas ao longo dos anos, como elencados na figura 1.

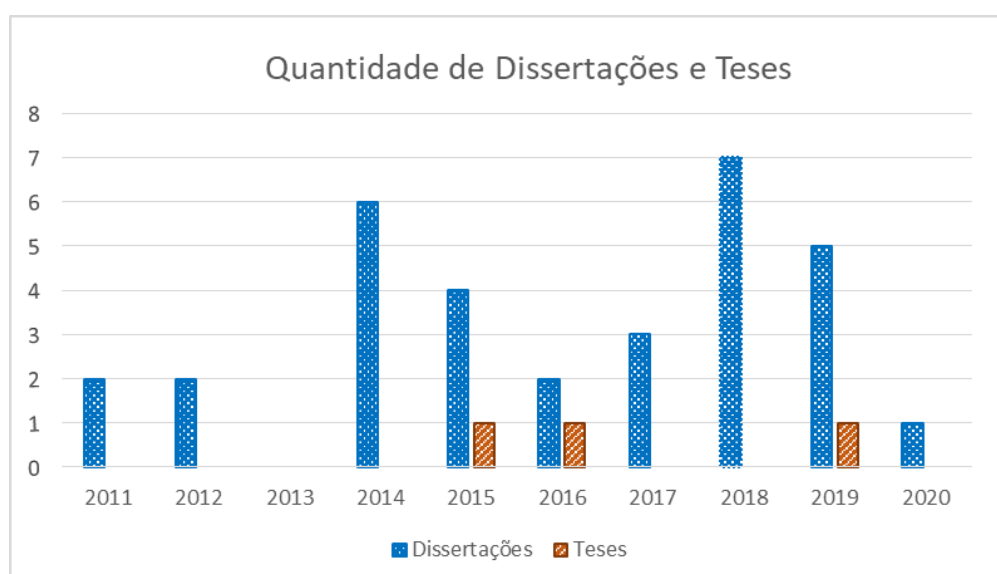

Figura 1 - Distribuição das dissertações e teses produzidas no Brasil no período de 2011 a 2020 (disponíveis no Banco de Teses e Dissertações da CAPES e na BDTD Brasileira).

Fonte: Produção dos autores (2021)

As produções de mestrado apresentam-se em maior quantidade representando mais de 90\% das pesquisas analisadas neste estudo. Verificamos uma maior quantidade de produções nos anos de 2014 e 2018. As três teses encontradas foram dos anos de 2015, 2016 e 2019. No ano de 2013 não foram encontradas dissertações ou teses.

No que diz respeito à distribuição das produções nas regiões do Brasil, observamos uma nítida concentração de estudos em alguns estados e em determinadas instituições (Figura 2). 


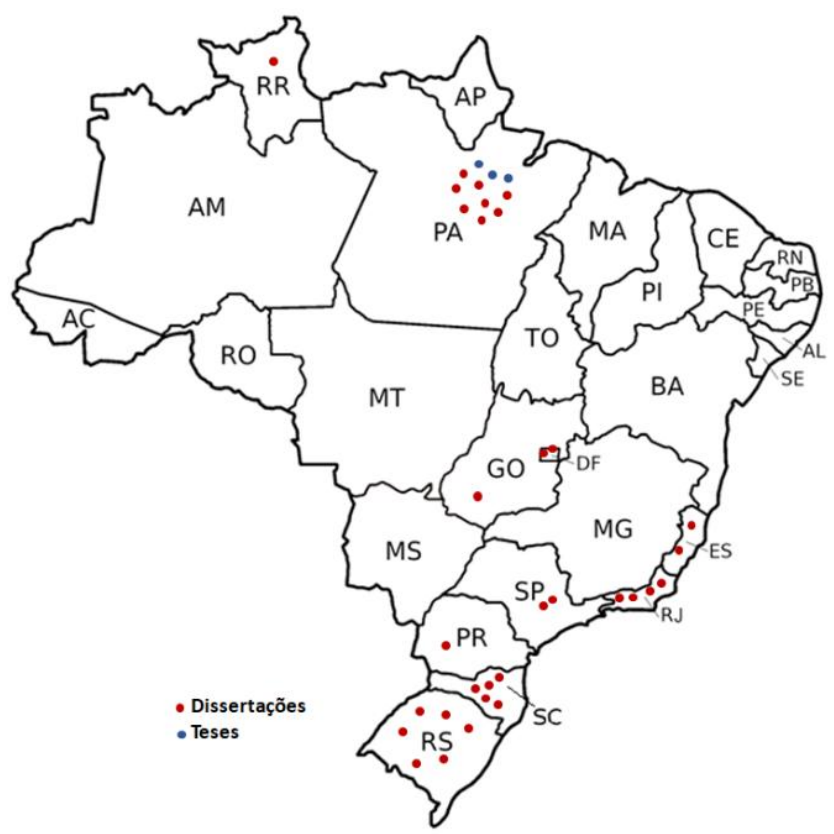

Figura 2 - Distribuição das pesquisas sobre Clubes de Ciências em Dissertações e Teses no Brasil entre os anos de 2011 e 2020 (disponíveis no Banco de Teses e Dissertações da CAPES e na BDTD Brasileira).

Fonte: Produção dos autores (2021)

As pesquisas de mestrado e doutorado relacionadas aos Clubes de Ciências, foram encontradas em quatro regiões do país no período investigado. A região Nordeste foi a única em que não identificamos nenhuma pesquisa. A maior parte das produções está concentrada nas regiões Norte e Sul (12 produções em cada região). Na região Norte, estão localizadas nos estados do Pará e de Roraima. Na região Sul, as pesquisas encontram-se distribuídas nos três estados de forma bastante uniforme. $\mathrm{Na}$ região Sudeste, as pesquisas encontram-se distribuídas em três dos quatro estados da região. Enquanto na região Centro-Oeste, localizamos três dissertações (uma no estado de Goiás e duas no Distrito Federal).

As 35 pesquisas analisadas neste estudo foram produzidas em nove estados brasileiros e no Distrito Federal por meio de Programas de Pós-Graduação vinculados a 13 instituições de ensino, sendo a maioria oriundas dos programas de Pós-Graduação voltados para o ensino e educação. Os estados que mais se destacaram na produção de dissertações e/ou teses na área de Clube de Ciências foram: Pará, seguido do Rio Grande do Sul e de Santa Catarina.

O estado do Pará é referência nacional em estudos sobre Clubes de Ciências, possuindo em funcionamento um projeto de extensão do Instituto de Educação Matemática e Científica (IEMCI) que funciona desde 1979. O Clube de Ciências da UFPA, além de estimular a iniciação científica em crianças e adolescentes, também proporciona a graduandos de diversos cursos da UFPA e de outras instituições a oportunidade de trabalhar com o ambiente de sala de aula e ganhar experiência em docência (CCIUFPA, 2020). 
Para uma melhor apresentação e discussão dos dados foi realizada a codificação das produções, dessa forma, as dissertações receberam códigos de D1 a D32, enquanto as teses receberam o código T1, T2 e T3. Detalhamos no Quadro 1 os principais dados das produções indicando o ano, código, autor, instituição e o título da dissertação ou tese.

\begin{tabular}{|c|c|c|c|c|}
\hline Ano & Código & Autor & Instituição & \begin{tabular}{|c|} 
Título \\
\end{tabular} \\
\hline \multirow[b]{2}{*}{$\overline{\widetilde{d}}$} & D1 & $\begin{array}{l}\text { SANTOS, J. } \\
\text { K. R. }\end{array}$ & UFPA & $\begin{array}{l}\text { Oportunidades de aprender sobre pesquisa na iniciação científica } \\
\text { júnior de uma bolsista no clube de ciências da UFPA }\end{array}$ \\
\hline & D2 & $\begin{array}{l}\text { MENEGASSI, } \\
\text { F. J. }\end{array}$ & PUCRS & $\begin{array}{l}\text { Um clube de ciências como espaço não formal de educação docente: } \\
\text { importância na formação inicial e continuada de professores de } \\
\text { biologia }\end{array}$ \\
\hline \multirow{2}{*}{$\stackrel{\sim}{\stackrel{2}{\sim}}$} & D3 & MENEZES, C. & FURB & $\begin{array}{l}\text { Clubes de ciências: contribuições para a educação científica nas } \\
\text { escolas da rede municipal de ensino de Blumenau - SC }\end{array}$ \\
\hline & D4 & $\begin{array}{l}\text { SOUZA, N. P. } \\
\text { S. }\end{array}$ & UNIRIO & $\begin{array}{l}\text { O ensino de ciências e os clubes de ciências na perspectiva da } \\
\text { alfabetização científica no ambiente escolar }\end{array}$ \\
\hline \multirow{6}{*}{$\stackrel{ \pm}{\triangleright}$} & D5 & LONGHI, A. & FURB & $\begin{array}{l}\text { Clube de ciências: espaço para a educação científica de estudantes do } \\
\text { ensino médio a partir do "projeto ENERBIO - energia da } \\
\text { transformação" }\end{array}$ \\
\hline & D6 & $\begin{array}{l}\text { GREIN, A. C. } \\
\text { V. }\end{array}$ & UTFPR & $\begin{array}{l}\text { Desenvolvimento de senso crítico, analítico e científico em alunos } \\
\text { participantes de clube de ciências. }\end{array}$ \\
\hline & D7 & BUCH, G. M. & FURB & $\begin{array}{l}\text { Clubes de ciências vinculados ao projeto "ENERBIO - energia da } \\
\text { transformação": ações para a alfabetização científica de estudantes do } \\
\text { ensino médio }\end{array}$ \\
\hline & D8 & DIAS, L. C. S. & UFF & $\begin{array}{l}\text { Clube de ciências e atividades lúdicas: impacto na formação de } \\
\text { professores das séries iniciais do ensino fundamental }\end{array}$ \\
\hline & D9 & $\begin{array}{l}\text { CANIÇALI, } \\
\text { M. A. F. }\end{array}$ & IFES & $\begin{array}{l}\text { Análise pedagógica do clube de ciências como extensão escolar nos } \\
\text { anos finais do ensino fundamental: em busca da alfabetização } \\
\text { científica com enfoque CTSA }\end{array}$ \\
\hline & D10 & $\begin{array}{l}\text { ALMEIDA, R. } \\
\text { C. }\end{array}$ & IFES & $\begin{array}{l}\text { Clube de ciências no ensino médio público para alfabetização } \\
\text { científica: aspectos pedagógicos à luz da pedagogia da práxis e do } \\
\text { movimento CTSA }\end{array}$ \\
\hline \multirow{5}{*}{$\frac{n}{i}$} & D11 & $\begin{array}{l}\text { ŚCHLEICH, } \\
\text { Á. P. }\end{array}$ & PUCRS & $\begin{array}{l}\begin{array}{l}\text { Educação ambiental em um clube de ciências, utilizando } \\
\text { geotecnologias }\end{array} \\
\end{array}$ \\
\hline & D12 & $\begin{array}{l}\text { FERREIRA, } \\
\text { A. C. }\end{array}$ & UNISAL & $\begin{array}{l}\text { Conhecimento comunitário e letramento científico: análise do "clube } \\
\text { de ciências" de uma escola confessional de Hortolândia - SP }\end{array}$ \\
\hline & D13 & $\begin{array}{l}\text { ADRIANO, G. } \\
\text { A. C. }\end{array}$ & FURB & $\begin{array}{l}\text { A aprendizagem e o desenvolvimento de crianças a partir da } \\
\text { implantação de um clube de ciências em uma escola de tempo integral } \\
\text { no município de Blumenau (SC) }\end{array}$ \\
\hline & D14 & $\begin{array}{l}\text { SILVA, P. S. } \\
\text { C. }\end{array}$ & IFRJ & $\begin{array}{l}\text { Clube de ciências como instrumento de divulgação científica e } \\
\text { melhora do rendimento escolar }\end{array}$ \\
\hline & $\mathrm{T} 1$ & $\begin{array}{l}\text { LIMA, D. D. } \\
\text { R. S. }\end{array}$ & UFPA & $\begin{array}{l}\text { Clube de ciências da UFPA e docência: experiências formativas desde } \\
\text { a infância }\end{array}$ \\
\hline \multirow{3}{*}{$\frac{0}{\stackrel{i}{\sigma}}$} & $\mathrm{T} 2$ & $\begin{array}{l}\text { PAIXÃO, C. } \\
\text { C. }\end{array}$ & UFPA & $\begin{array}{l}\text { Experiências docentes no clube de ciências da UFPA contribuições à } \\
\text { renovação do ensino de ciências }\end{array}$ \\
\hline & D15 & $\begin{array}{l}\text { MARTINS, F. } \\
\text { R. }\end{array}$ & UFF & $\begin{array}{l}\text { Clube de ciências como ferramenta de iniciação científica para alunos } \\
\text { superdotados e/ou com vocação científica }\end{array}$ \\
\hline & D16 & $\begin{array}{l}\text { ALBUQUERQ } \\
\text { UE, N. F. }\end{array}$ & PUCRS & Clubes de ciências: contribuições para uma formação contemporânea \\
\hline \multirow{3}{*}{ ळ) } & D17 & \begin{tabular}{l|} 
FERREIRA \\
NETO, J. A.
\end{tabular} & UFPA & $\begin{array}{l}\text { Ser ou não ser como nossos professores de ciências: proposição para } \\
\text { uma intervenção afetiva no estágio do clube de ciências da UFPA }\end{array}$ \\
\hline & D18 & $\begin{array}{l}\text { COUTO, M. } \\
\text { R. A. M. }\end{array}$ & UNB & $\begin{array}{l}\text { Os clubes de ciências e a iniciação à ciência: uma proposta de } \\
\text { organização no ensino médio }\end{array}$ \\
\hline & D19 & RIBEIRO, R. & UFPA & Interdisciplinaridade e subjetividade: experiências de ensino \\
\hline
\end{tabular}




\begin{tabular}{|c|c|c|c|c|}
\hline & & A. & & vivenciadas por professores egressos do clube de ciências da UFPA \\
\hline \multirow{7}{*}{$\stackrel{\infty}{\frac{\infty}{2}}$} & D20 & $\begin{array}{l}\text { LIPPERT, B. } \\
\text { G. }\end{array}$ & PUCRS & $\begin{array}{l}\text { Clube de ciências e unidade de aprendizagem sobre educação } \\
\text { ambiental: contribuições para um pensar ecológico }\end{array}$ \\
\hline & D21 & NERY, G. L. & UFPA & $\begin{array}{l}\text { Interações discursivas e a experimentação investigativa no clube de } \\
\text { ciências Prof }{ }^{\circ} \text {. Dr. Cristovam Wanderley Picanço Diniz }\end{array}$ \\
\hline & D22 & $\begin{array}{l}\text { SIQUEIRA, H. } \\
\text { C. C. }\end{array}$ & UFPA & $\begin{array}{l}\text { Ensino de ciências por investigação: interações sociais e autonomia } \\
\text { moral na construção do conhecimento científico em um clube de } \\
\text { ciências }\end{array}$ \\
\hline & D23 & $\begin{array}{l}\text { CATARDO, L. } \\
\text { S. }\end{array}$ & PUCRS & $\begin{array}{l}\text { A implantação de clubes de ciências nas escolas do campo: uma } \\
\text { ferramenta complementar na melhoria da qualidade do ensino de } \\
\text { ciências }\end{array}$ \\
\hline & D24 & $\begin{array}{l}\text { FARIA, S. L. } \\
\text { B. }\end{array}$ & UNB & $\begin{array}{l}\text { Clube de ciências: uma análise do processo de implementação em } \\
\text { uma escola de ensino médio }\end{array}$ \\
\hline & D25 & $\begin{array}{l}\text { TEODORO, S. } \\
\text { D. E. O. }\end{array}$ & UNIFESP & $\begin{array}{l}\text { A utilização do clube de ciências forenses na promoção da } \\
\text { alfabetização científica: estudo de caso }\end{array}$ \\
\hline & D26 & LUNELLI, T. & & $\begin{array}{l}\text { E se aulas de ciências que acontecem nos anos iniciais da escola se } \\
\text { transformassem em um clube de ciências? contribuições para } \\
\text { educação científica de crianças }\end{array}$ \\
\hline \multirow{6}{*}{ 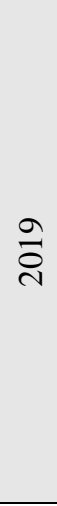 } & D27 & $\begin{array}{l}\text { BARBOSA, D. } \\
\text { F. S. }\end{array}$ & UFPA & $\begin{array}{l}\text { Perguntas do professor monitor e a alfabetização científica de alunos } \\
\text { em interações experimentais investigativas de um clube de ciências }\end{array}$ \\
\hline & D28 & COSTA, G. G. & PUCRS & $\begin{array}{l}\text { Contribuições da monitoria em clubes de ciências para o } \\
\text { aprimoramento pessoal e cognitivo do aluno-monitor }\end{array}$ \\
\hline & D29 & $\begin{array}{l}\text { TRESSOLDI, } \\
\text { G. B. }\end{array}$ & UERR & $\begin{array}{l}\text { Clube de ciências no incentivo ao letramento científico em uma escola } \\
\text { do ensino fundamental II no município de Boa Vista - Roraima }\end{array}$ \\
\hline & D30 & $\begin{array}{l}\text { OLIVEIRA, L. } \\
\text { C. S. }\end{array}$ & UFPA & $\begin{array}{l}\text { Alfabetização científica através da experimentação investigativa em } \\
\text { um clube de ciências }\end{array}$ \\
\hline & D31 & $\begin{array}{l}\text { MONTEIRO, } \\
\text { J. M. C. }\end{array}$ & UFPA & $\begin{array}{l}\text { Condições antrópicas para o uso de analogias na experimentação } \\
\text { investigativa em um clube de ciências }\end{array}$ \\
\hline & $\mathrm{T} 3$ & $\begin{array}{l}\text { ROCHA, C. } \\
\text { J.T. }\end{array}$ & UFPA & $\begin{array}{l}\text { Desenvolvimento profissional docente de mestrandos em perspectivas } \\
\text { do ensino por investigação em um clube de ciências da UFPA }\end{array}$ \\
\hline ્ֻণి & D32 & ALVES, R. R. & UEG & ibuições para a alfabetização científica \\
\hline
\end{tabular}

Quadro 1- Pesquisas sobre Clubes de Ciências em Dissertações e Teses entre os anos de 2011 a 2020 (disponíveis no Banco de Teses e Dissertações da CAPES e na BDTD Brasileira).

Fonte: Produção dos autores (2021)

\subsection{Participantes das pesquisas sobre Clube de Ciências}

Para uma melhor compreensão acerca dos principais integrantes dos estudos sobre Clube de Ciências, buscamos identificar os participantes dessas pesquisas nas dissertações e teses realizadas no Brasil nos últimos anos (2011 a 2020).

Dessa forma, com base na análise das dissertações e teses, realizamos o levantamento dos participantes das pesquisas sobre Clube de Ciências. Estes foram identificados conforme evidenciado abaixo no quadro 2.

\begin{tabular}{|l|l|}
\hline Participantes das pesquisas sobre Clube de Ciências & Código das produções científicas \\
\hline Estudantes do Ensino Fundamental I - $1^{\circ}$ ao $5^{\circ}$ ano & D13, D26 e D30. \\
\hline Estudantes do Ensino Fundamental II $-6^{\circ}$ ao $9^{\circ}$ ano & D1, D4, D6, D9, D11, D12, D14, D15, D16, \\
\hline
\end{tabular}




\begin{tabular}{|l|l|}
\hline & $\begin{array}{l}\text { D20, D21, D22, D23 D25, D27, D28, D29, } \\
\text { D30, D31 e D32. }\end{array}$ \\
\hline Estudantes do Ensino Médio & D5, D10, D15, D18 e D24. \\
\hline $\begin{array}{l}\text { Estudantes do Ensino Superior/ Professores egressos de } \\
\text { programas que atuaram em Clubes de Ciências/ Professores } \\
\text { responsáveis pelos Clubes de Ciências }\end{array}$ & $\begin{array}{l}\text { D2, D3, D7, D8, D13, D17, D19, D21, D27, } \\
\text { T1, T2 e T3. }\end{array}$ \\
\hline
\end{tabular}

Quadro 2- Participantes das pesquisas sobre Clube de Ciências nas Dissertações e Teses analisadas entre os anos de 2011 e 2020 (disponíveis no Banco de Teses e Dissertações da CAPES e na BDTD Brasileira). Fonte: Produção dos autores (2021)

Observamos que a maioria das produções científicas envolvem os estudantes dos anos finais do Ensino Fundamental, as pesquisas buscam compreender aspectos relacionados à iniciação (D1) e à Alfabetização Científica (D4, D9, D25, D27, D30 e D32), assim como buscam estudar o processo de construção do conhecimento científico pelos estudantes (D11, D12, D2) com o desenvolvimento de ações que visam a ampliação da prática e de atividades investigativas e experimentais. As pesquisas também discutem o funcionamento (criação e desenvolvimento) dos Clubes no Ensino Fundamental (anos finais) (D15, D23, D29, D32).

As pesquisas voltadas aos estudantes dos anos iniciais do Ensino Fundamental buscam o desenvolvimento das crianças e a promoção da Alfabetização Científica no Clube de Ciências, desenvolvendo atividades lúdicas com a utilização de materiais alternativos.

No Ensino Médio, as pesquisas (D5, D18 e D24) estão voltadas para a iniciação, alfabetização e divulgação científica dos jovens e possuem enfoques de ensino voltados para o aprofundamento das Ciências da Natureza (Química, Física e Biologia). As dissertações (D5, D10 e D15) discutem também aspectos relacionados ao funcionamento dos Clubes de Ciências no Ensino Médio.

Com relação aos estudantes do Ensino Superior e professores que atuam nos Clubes de Ciências, os estudos se concentram principalmente nas contribuições dos Clube de Ciências nos processos de formação inicial (D17, D19, D21 e T1) e formação continuada dos professores (D2, D8 T2, T3). Outros estudos trouxeram reflexões sobre as contribuições do Clube de Ciências na aprendizagem dos alunos, de acordo com as concepções dos Professores (D3, D7, D10 e D13).

\subsection{Objetivos de investigação das pesquisas}

Buscamos identificar os objetivos centrais das pesquisas, entendendo que estes sinalizam o foco principal a ser abordado pelos autores. Na sequência, partimos para a identificação das unidades de registro presentes nos objetivos das dissertações e teses, 
relacionando-as com o código da produção científica. A partir das unidades de registro, emergiram as categorias relacionadas aos enfoques dos objetivos das produções científicas analisadas, conforme apresentamos a seguir (Quadro 3).

\section{$1^{\circ}$ Grupo- Unidades de registro identificadas nos objetivos das dissertações e teses}

D4- Relacionar os projetos do Clube de Ciências com os processos de alfabetização científica.

D7- Identificar e analisar as contribuições de um Clube de Ciências para o processo de alfabetização científica dos estudantes envolvidos.

D9- Analisar os aspectos pedagógicos de um clube de ciências buscando indícios de práticas pedagógicas inovadoras voltadas para a alfabetização científica.

D24- Visando alfabetizar cientificamente seus membros.

D25- Como o clube de ciências forenses poderia contribuir no desenvolvimento da alfabetização científica de alunos.

D27- Analisar as perguntas dos Professores Monitores, almejando Indicadores de Alfabetização Científica.

D30- Analisar como se desenvolve a Alfabetização Científica entre estudantes do ensino fundamental que participaram do Clube de Ciências.

D32- Verificar sua eficácia do Clube de Ciências para promover a alfabetização científica de alunos.

D11- Compreender como ocorre a construção de conhecimentos pelos alunos.

D12- Estabelecer relações entre o conhecimento comunitário e o conhecimento científico.

D13- Analisar o processo de elaboração de conceitos científicos por crianças.

D22- Construção do conhecimento científico por alunos participantes de um Clube de Ciências.

D6- Analisar como um Clube de Ciências permite aos alunos participantes desenvolverem-se crítica, analítica e cientificamente.

D3- Identificar e analisar as contribuições de um Clube de Ciências para o processo de educação científica.

Categoria: Promoção da Alfabetização Científica e construção do conhecimento científico dos alunos

\section{$2^{\circ}$ Grupo- Unidades de registro identificadas nos objetivos das dissertações e teses}

D5- Investigar o processo de implantação e desenvolvimento de quatro Clubes de Ciências a partir do "Projeto ENERBIO: Energia da Transformação".

D7- Analisar o processo de implantação e desenvolvimento dos Clubes de Ciências vinculados ao Projeto ENERBIO

D10- Estudar o potencial pedagógico do desenvolvimento do projeto de extensão escolar chamado "Clube de Ciências Escolar".

D15- Criar e avaliar o programa "Clube de Ciências".

D23- Realizar a implantação de Clubes de Ciências nas Escolas do Campo como ferramenta complementar para o ensino de ciências.

D24- Planejar, desenvolver e avaliar a implementação de um Clube de Ciências em uma escola pública. D26- Elaborar referentes que possam subsidiar a criação e o desenvolvimento de um Clube de Ciências.

D29- Avaliar as contribuições da implantação de um Clube de Ciências.

D32- Propor e avaliar uma estrutura de clube de ciências.

Categoria: Investigações sobre desenvolvimento dos Clubes de Ciências.

$3^{\circ}$ Grupo- Unidades de registro identificadas nos objetivos das dissertações e teses

D2- Compreender a contribuição dos Clubes de Ciências na educação em Ciências e na formação permanente de professores de Ciências Biológicas.

D8- Analisar o impacto da implementação de atividades científicas lúdicas na formação de professores.

D17- Desenvolvimento e estruturação de proposições de intervenção afetiva que pudesse ser utilizada durante o estágio orientado de regência.

D19- Investigar a compreensão de professores egressos.

D21- Dando subsídios para o professor-monitor refletir entre sua própria prática.

T1- Como constroem e modificam o seu ser e fazer docente no presente.

T2- Investigar para compreender em que termos experiências docentes desenvolvidas no clube de ciências da UFPA constituem contribuições à renovação do ensino de ciências.

T3- Investigar o Desenvolvimento Profissional Docente. 
Categoria: Formação de professores

$4^{\circ}$ Grupo- Unidades de registro identificadas nos objetivos das dissertações e teses

D22- Identificar os princípios de autonomia moral por alunos participantes de um Clube de Ciências.

D16- Desenvolvimento de atributos recomendados para formação contemporânea dos sujeitos.

D6- Analisar como um Clube de Ciências permite aos alunos participantes desenvolverem-se crítica, analítica e cientificamente.

D28- Compreender a influência da monitoria em Clube de Ciências para a potencialização da formação integral do aluno-monitor.

Categoria: Contribuições na formação dos estudantes

$5^{\circ}$ Grupo- Unidades de registro identificadas nos objetivos das dissertações e teses

D1- Acompanhar uma díade orientadora-bolsista de Iniciação Científica Junior ao longo de um ano, caracterizando as principais oportunidades de aprender e produzir sentidos subjetivos sobre a pesquisa.

D18- Investigar os Clubes de Ciências como estratégia de Iniciação à Ciência na Educação Básica.

D14- Relatar como um clube de ciências pode ser um mecanismo de divulgação científica e de melhora do rendimento escolar.

Categoria: Espaço para iniciação e divulgação científica.

Quadro 3- Categorização dos objetivos de investigação das Dissertações e Teses analisadas entre os anos de 2011 e 2020 (disponíveis no Banco de Teses e Dissertações da CAPES e na BDTD Brasileira).

Fonte: Produção dos autores (2021)

A análise dos objetivos por meio do processo de categorização revelou-nos algumas tendências de estudos, possibilitando identificar cinco categorias de acordo com a questão central de enfoque dos trabalhos. Sendo elas: 1) Promoção da Alfabetização Científica e construção do conhecimento científico dos alunos; 2) Investigações sobre desenvolvimento dos Clubes de Ciências; 3) Formação de professores; 4) Contribuições na formação dos estudantes; e 5) Espaço para iniciação e divulgação científica.

A categoria Promoção da Alfabetização científica e construção do conhecimento científico dos alunos caracteriza os objetivos que buscam estudar o Clube como um espaço facilitador da Alfabetização Científica e construção do conhecimento científico. De acordo com Oliveira, Pinto e Oaigen (2012), o Clube de Ciências tem se mostrado eficiente na construção de competências e habilidades para a inserção de estudantes no pensar científico, contribuindo para a construção do conhecimento científico e, consequentemente, para uma melhor aprendizagem em ciências.

Para Vitor e Silva (2017), a proposta de Alfabetização Científica consiste em buscar construir conhecimentos científicos de forma mais ampla e atraente para, assim, contribuir na formação de indivíduos capazes de discutir sobre múltiplos assuntos e tomar decisões criticamente.

A categoria Investigações sobre desenvolvimento dos Clubes de Ciências representa os objetivos propostos a criar, analisar e avaliar a implantação e desenvolvimento de Clubes de 
Ciências. Assim, buscam estudar como ocorre o processo de criação e implementação de novos Clubes de Ciências e ainda verificar o andamento de Clubes já existentes. A proposta da criação dos Clubes de Ciências (MANCUSO; LIMA; BANDEIRA, 1996) surgiu exatamente para auxiliar na melhoraria do ensino de ciências, suprindo, assim, as necessidades em relação ao conhecimento que os estudantes buscam além da sala de aula (BUCH; SCHROEDER, 2011). Sendo importante a realização de estudos voltados a discutir a criação e funcionamento dos Clubes de Ciências.

No que diz respeito à categoria Formação de professores, representa as produções que se dedicaram a analisar, observar o Clube de Ciências como espaço formativo para futuros professores e professores em atuação. Dessa forma, O Clube de Ciências tem sido apontado como um espaço propício para a transformação e constituição do sujeito professor em suas diferentes dimensões. Além de estar relacionado com a renovação da prática de ensino, a partir das iniciativas e experiências vivenciadas em prol do ensino de ciências (PAIXÃO, 2016).

Nesse sentido, os Clubes de Ciências se apresentam como ambientes de formação inicial de professores, uma vez que a maioria dos professores estagiários dos Clubes são estudantes universitários que têm oportunidades de experimentar diferentes metodologias de ensino e assim ter contato com os estudantes da Educação Básica (NUNES, 2016). O Clube de Ciências também é um ambiente de formação continuada de professores, pois os professores em atuação também participam do processo, tendo, nesse espaço, uma oportunidade de formação. No Clube, o professor tem oportunidade e maior liberdade para criar, propor atividades diversificadas, experimentar e refletir sobre a própria prática, constituindo um importante mecanismo de formação (PAIXÃO, 2008).

A categoria Contribuições na formação dos estudantes representa os objetivos das pesquisas que buscam investigar o Clube de Ciências como uma ferramenta que contribui para a formação dos estudantes nesses ambientes. Sedano e Carvalho (2017) defendem que o Clube de Ciências é uma estratégia metodológica que facilita e possibilita a formação da autonomia por propiciar aos alunos oportunidade de interagir, argumentar e discutir.

Nessa perspectiva, os Clubes de Ciências se apresentam como espaços que contribuem para a formação dos estudantes em diferentes aspectos, possibilitando o desenvolvimento de valores como a "solidariedade, fraternidade, consciência do compromisso social, de reciprocidade, de respeito ao próximo e de generosidade" (SANTOS; MORTIMER, 2002, p. 
5). Além de contribuir para a formação da criticidade, atitudes reflexivas, éticas e morais da ciência (SOUZA; SILVA; SIMÃO, 2016).

A participação no Clube de Ciências proporciona uma visão de mundo mais ampla aos alunos, que percebem novas possibilidades de atuação como cidadão e profissional, recebendo uma formação humana mais global, além daquela oferecida pela educação formal nas nossas salas de aula convencionais (SILVA et al., 2008).

A categoria Espaço para iniciação e divulgação científica compreende os objetivos relacionados ao Clube de Ciências como estratégia para a iniciação científica dos estudantes e como mecanismo de divulgação científica no ambiente escolar. Assim, o Clube de Ciências constitui-se como um espaço pedagógico extraclasse que possibilita a pesquisa e a iniciação científica, além de promover a divulgação científica dos trabalhos realizados pelos estudantes e professores no âmbito da comunidade escolar (SANTOS, et al., 2010; MANCUSO; LIMA; BANDEIRA, 1996).

\section{CONSIDERAÇÕES}

Esta revisão nos permitiu uma compreensão acerca das pesquisas sobre Clubes de Ciências produzidas no Brasil, em nível de mestrado e doutorado. Percebemos uma maior ocorrência de produções nos anos de 2014 e 2018, e que a maior parte das produções estão concentradas nas regiões Norte e Sul. As produções analisadas neste estudo foram produzidas em nove estados brasileiros e no Distrito Federal, por meio de Programas de Pós-Graduação vinculados a 13 instituições de ensino, sendo a maioria oriundas dos programas de PósGraduação voltados para o ensino e educação.

Com relação aos participantes das pesquisas sobre Clube de Ciências, a maior parte das produções científicas apresentaram os estudantes dos anos finais do Ensino Fundamental como participantes. Enquanto a segunda categoria de destaque foi a de pesquisas que tiveram foco Estudantes do Ensino Superior/ Professores egressos de programas que atuaram em Clubes de Ciências/ Professores responsáveis pelos Clubes de Ciências. Estudantes dos anos iniciais do Ensino Fundamental e do Ensino Médio também foram identificados como participantes nas pesquisas. Apontamos a que variedade de participantes observada nas pesquisas pode estar relacionada ao dinamismo dos clubes como espaços de ensinoaprendizagem que contribui tanto para formação dos estudantes da Educação Básica como para formação inicial e continuada de professores. 
Percebemos, por meio das análises dos objetivos, que os principais focos das pesquisas analisadas foram relacionados à Alfabetização Científica dos estudantes, assim como as contribuições dos Clubes de Ciências para a construção do conhecimento científico dos estudantes, por meio da ampliação da prática experimental e investigativa, buscando contribuir para a formação pessoal e científica desses alunos.

Nesse sentido, mais do que promover a Alfabetização Científica e contribuir para a construção do conhecimento científico, o Clube de Ciências busca propiciar aos clubistas uma compreensão crítica da realidade, tornando o aluno atuante no processo de ensinoaprendizagem, a partir de múltiplas perspectivas, passando a possuir um olhar científico sobre o mundo.

Portanto, as pesquisas demonstraram que os Clubes de Ciências contribuem para o ensino de ciências sendo uma importante estratégia para o processo de ensino-aprendizagem, uma vez que promove a iniciação, alfabetização e divulgação científica, contribuindo para a construção do conhecimento científico e para a formação pessoal e científica dos estudantes, além de se apresentar como um importante espaço para a formação docente.

\section{REFERÊNCIAS}

ABREU, A. R. P. Estratégias de desenvolvimento científico e tecnológico e a difusão da ciência no Brasil. In: CRESTANA, S. (Org.). Educação para a ciência: curso para treinamento em centros e museus de ciência. São Paulo: Editora Livraria da Física, 2001. p. 23-28.

BARDIN, L. Análise de conteúdo. São Paulo: Edições 70, 2011.

BAZO, R.; SANTIAGO, A. Investigación científica en la escuela: Ferias de ciências y tecnologia. Buenos Aires: Plus Ultra, 1981.

BIANCONI, M. L.; CARUSO, F. Educação não-formal. Ciência e Cultura, v. 57, n. 4, out./dez.2005, p. 20-20. Disponível em:

http://cienciaecultura.bvs.br/scielo.php?script=sci_arttext\&pid=S0009-67252005000400013.

Acesso em: 10 mai. 2020.

BRASIL. Ministério da Educação. Secretaria de Educação Básica. Programa Nacional de Apoio às Feiras de Ciências da Educação Básica Fenaceb. Brasília, DF, 2006. Disponível em: http://portal.mec.gov.br/seb/arquivos/pdf/EnsMed/fenaceb.pdf. Acesso em: 10 mai. 2020.

BUCH, G. M.; SCHROEDER, E. Clubes de Ciências Educação Científica: Concepções dos Professores Coordenadores da Rede Municipal de Ensino de Blumenau (SC). In:

ENCONTRO REGIONAL SUL DE ENSINO DE BIOLOGIA (EREBIO-SUL), n. 5, 2011, Londrina. Anais[...]. Londrina: UEL, 2011. p. 1-10. 
CCIUFPA - Clube de Ciências da Universidade Federal do Pará. Histórico: Clube de Ciências. Disponível em: http://www.iemci.ufpa.br/index.php/cciufpa. Acesso em: 10 mai. 2020 .

COSTA, A. Clubes de Ciências "Pequeno Príncipe"- uma realidade na área rural. Revista do PROCIRS. Porto Alegre: FDRH, v.1, 1988, p.38.

FERNANDES, L. A.; GOMES, J.M.M. Relatórios de pesquisa nas ciências sociais: características e modalidades de investigação. Contexto, Porto Alegre, v. 3, n. 4, 2003.

FRANCO, M. L. P. B. Análise de conteúdo. 3. ed. Brasília: Liber Livro Editora, 2008.

FULLAN, M. Change forces: the sequel. London: Falmer, 1999.

GADOTTI, M. Perspectivas atuais da educação. Porto Alegre: Artes Médicas, 2000.

GIL, A. C. Métodos e técnicas de pesquisa social. 5.ed. São Paulo: Atlas, 1999.

GOHN, M. G. Educação não formal, aprendizagens e saberes em processos participativos. Investigar em Educação, (1), 2014, p.35-50.

GOMES, C. M. B. Aspectos Psíquicos e Políticos do Ensino no Clube de Ciências. Revista do PROCIRS. Porto Alegre: FDRH, v.1, n.1, 1988, p.30.

KRASILCHIK, M. O professor e o currículo das ciências. São Paulo: EPU, 1987.

MANCUSO, R.; LIMA, V. M. do R.; BANDEIRA, V. A. Clubes de Ciências: criação, funcionamento, dinamização. Porto Alegre: SE/CECIRS, 1996.

MARQUES, A. C. T.; MARANDINO, M. Alfabetização Científica, crianças e espaços de educação não formal: diálogos possíveis. Revista Educação e Pesquisa. São Paulo, v. 44. p. 1-19, 2018. Disponível em: https://www.revistas.usp.br/ep/article/view/143528. Acesso em: 10 fev. 2021.

MENEGASSI, F. J. et al. Relações Entre Concepções Epistemológicas e Pedagógicas de Licenciados e Professores que Atuam em Clubes de Ciências. In: Mostra de Pesquisa da PósGraduação. 5, 2010, Porto Alegre. Anais[...]. Porto Alegre. Edipucrs, 2010.

NEVES, J. L. Pesquisa Qualitativa - características, usos e possibilidades. Caderno de Pesquisa em Administração, São Paulo, v. 1, no. 3, 1996.

NUNES, J. B. M. Aprendizagens docentes no CCIUFPA: sentidos e significados das práticas antecipadas assistidas e em parceria na formação inicial de professores de ciências. 2016. 246 p. Dissertação (Mestrado) - Universidade Federal do Pará, Instituto de Educação Matemática e Científica, Programa de Pós-Graduação em Educação em Ciências e Matemáticas, Belém, 2016. 
OLIVEIRA, R.; PINTO, J. M. O.; OAIGEN, E. R. Clubes de ciências: ferramenta educacional para a construção de caminhos para a iniciação à Educação Científica. IX ANPED SUL, UCS, Caxias do Sul, 2012.

PAIXÃO, C. C. Experiências Docentes no Clube de Ciências da UFPA: Contribuições a Renovação do Ensino e Ciências. 2016. 151f. Tese (Doutorado em Educação em Ciências)Universidade Federal do Pará, Belém, 2016. Disponível em:

https://bdtd.ibict.br/vufind/Record/UFPA_af86a695a6a7cd26e2d3ffdb58600cd4. Acesso em: 13 jan. 2021.

PAIXÃO, C. C. Narrativa autobiográfica de formação: processos de vir a ser professor de ciências. Belém: NPADC, 2008. Dissertação (Mestrado) - Universidade Federal do Pará, Instituto de Educação Matemática e Científica, Programa de Pós-Graduação em Educação em Ciências e Matemáticas, Belém, 2008.

RAMALHO, P. F. N.; et al. Clubes de Ciências: educação científica aproximando universidade e escolas públicas no litoral paranaense. In: Encontro Nacional de Pesquisa em Educação em Ciências, 8., 2011, Campinas. Anais[...]. Belo Horizonte: ABRAPEC, 2011. p. 1-11. Disponível em: http://abrapecnet.org.br/atas_enpec/viiienpec/resumos/R1074-1.pdf. Acesso em: 10 fev. 2021.

SANTOS, J.; et al. Estruturação e consolidação de Clubes de Ciências nas escolas públicas do litoral do Paraná. In:II Simpósio Nacional de Ensino de Ciências e Tecnologia. Anais[...]. Curitiba. Universidade Federal do Paraná, 2010.

SANTOS, W. L. P. dos; MORTIMER, E. F. Uma Análise de Pressupostos Teóricos da Abordagem CT-S (Ciência - Tecnologia - Sociedade) no Contexto da Educação Brasileira.

Ensaio - Pesquisa em Educação em Ciências. v. 2, n. 2, dez. 2002. Disponível em: https://www.scielo.br/j/epec/a/QtH9SrxpZwXMwbpfpp5jqRL/?format=pdf\&lang=pt. Acesso em: 10 fev. 2021.

SEDANO, L.; CARVALHO, A. M. P. Ensino de Ciências por Investigação: Oportunidades de interação Social e sua Importância para a construção da autonomia moral.

Alexandri: Revista de Educação em Ciência e Tecnologia. Florianópolis, v. 10, n. 1, p. 199-220, maio, 2017. https://doi.org/10.5007/1982-5153.2017v10n1p199

SILVA, J. B.; et al. Projeto criação Clubes de Ciências. Revista Conexão UEPG, Ponta Grossa, v. 4, n. 1, 2008. Disponível em:

https://revistas2.uepg.br/index.php/conexao/article/view/3811. Acesso em: 20 fev. 2021.

SILVA, J. B.; BORGES, C. P. F. Clubes de Ciências como um ambiente de formação profissional de professores. XVIII Simpósio Nacional de Ensino de Física - SNEF, Vitória, 2009.

SOUSA, A. I.; CORRÊA, E. J.; TUTTMAN, M. T. Panorama dos programas de bolsas de extensão existentes nas instituições de ensino superior públicas brasileiras. Revista Brasileira de Extensão Universitária, v.1, n.1, p. 16-20, jul/dez. 2003. https://doi.org/10.36661/2358$\underline{0399.2003 v 1 i 1.866}$ 
SOUZA, R. F. V.; DIAS, F. E. Proposta de melhoria da formação de professores da educação básica através da iniciação a docência em um clube de ciências e cultura. Revista Iluminart, IFSP, n. 7, 2011. Disponível em:

http://revistailuminart.ti.srt.ifsp.edu.br/index.php/iluminart/article/view/122. Acesso em: 09 jan. 2021.

SOUZA, R.; SILVA, V. L. S.; SIMÃO, V. L. O clube de ciências como espaço de (eco)formação e criatividade. Revista Dynamis, v.22, n.1, p.74-85, 2016. Disponível em: https://bu.furb.br/ojs/index.php/dynamis/article/view/6480. Acesso em: 15 jan. 2021.

TOMIO, D.; HERMANN, A. P. Mapeamento dos clubes de ciências da América Latina e construção do site da Rede Internacional de Clube de Ciências. Ensaio: Pesquisa em

Educação em Ciências, v. 21, n. 1, p. 1-23, 2019. Disponível em:

https://www.scielo.br/j/epec/a/6PCBj3FRcy3Md7nWWbvVWVD/?lang=pt. Acesso em: 09 jan. 2021.

TRIVINOS, A. N. S. Introdução à Pesquisa em Ciências Sociais: a Pesquisa Qualitativa em Educação - O Positivismo, A Fenomenologia, O Marxismo. 1.ed. São Paulo: Atlas, 2009.

VITOR, F. C.; SILVA, A. P. B. Alfabetização e educação científicas: consensos e controvérsias. Revista Brasileira de Estudos Pedagógicos, v. 98, n. 249, p. 410-427, 2017. Disponível em:

https://www.scielo.br/j/rbeped/a/dRphmt4jn3HtCCbYLSdX6qc/abstract/?lang=pt. Acesso em: 09 jan. 2021.

\section{APÊNDICE 1}

\section{AGRADECIMENTOS}

À Universidade Federal do Tocantins e ao Programa de Pós-Graduação em Ensino de Ciências e Matemática (PPGecim). Em especial ao professor Dr. Gecilane Ferreira (In memoriam) que foi um exímio professor e o principal idealizador do PPGecim e da implantação de Clubes de Ciências no estado do Tocantins.

\section{FINANCIAMENTO}

Não se aplica.

\section{CONTRIBUIÇÕES DE AUTORIA}

Resumo/Abstract/Resumen: Nilciane Pinto Ribeiro de Sousa; Rodney Haulien Oliveira Viana; Gecilane Ferreira; Leonardo Cipriano Nogueira.

Introdução: Nilciane Pinto Ribeiro de Sousa; Rodney Haulien Oliveira Viana; Gecilane Ferreira; Leonardo Cipriano Nogueira.

Referencial teórico: Nilciane Pinto Ribeiro de Sousa; Rodney Haulien Oliveira Viana; Gecilane Ferreira; Leonardo Cipriano Nogueira.

Análise de dados: Nilciane Pinto Ribeiro de Sousa; Rodney Haulien Oliveira Viana; Gecilane Ferreira; Leonardo Cipriano Nogueira.

Discussão dos resultados: Nilciane Pinto Ribeiro de Sousa; Rodney Haulien Oliveira Viana; Gecilane Ferreira; Leonardo Cipriano Nogueira.

Conclusão e considerações finais Nilciane Pinto Ribeiro de Sousa; Rodney Haulien Oliveira Viana; Gecilane Ferreira; Leonardo Cipriano Nogueira.

Referências: Nilciane Pinto Ribeiro de Sousa; Rodney Haulien Oliveira Viana; Gecilane Ferreira; Leonardo Cipriano Nogueira.

Revisão do manuscrito: Nilciane Pinto Ribeiro de Sousa; Rodney Haulien Oliveira Viana; Gecilane Ferreira; Leonardo Cipriano Nogueira. 
Aprovação da versão final publicada: Nilciane Pinto Ribeiro de Sousa; Rodney Haulien Oliveira Viana; Leonardo Cipriano Nogueira.

\section{CONFLITOS DE INTERESSE}

Os autores declararam não haver nenhum conflito de interesse de ordem pessoal, comercial, acadêmico, político e financeiro referente a este manuscrito.

\section{DISPONIBILIDADE DE DADOS DE PESQUISA}

O conjunto de dados que dá suporte aos resultados da pesquisa foi publicado no próprio artigo.

\section{CONSENTIMENTO DE USO DE IMAGEM}

Não se aplica.

\section{APROVAÇÃO DE COMITÊ DE ÉTICA EM PESQUISA \\ Não se aplica.}

\section{COMO CITAR - ABNT}

SOUSA, Nilciane Pinto Ribeiro de; VIANA, Rodney Haulien Oliveira; FERREIRA, Gecilane; NOGUEIRA, Leonardo Cipriano. Clube de ciências: um olhar a partir das teses e dissertações brasileiras. REAMEC - Rede Amazônica de Educação em Ciências e Matemática. Cuiabá, v. 9, n. 3, e21079, set./dez., 2021. http://dx.doi.org/10.26571/reamec.v9i3.12435

\section{COMO CITAR - APA}

Sousa, N. P. R. De, Viana, R. H. O., Ferreira, G., Nogueira, L. C. (2021). Clube de ciências: um olhar a partir das teses e dissertações brasileiras. REAMEC - Rede Amazônica de Educação em Ciências e Matemática, 9(3), e21079. http://dx.doi.org/10.26571/reamec.v9i3.12435

\section{LICENÇA DE USO}

Licenciado sob a Licença Creative Commons Attribution-NonCommercial 4.0 International (CC BY-NC 4.0). Esta licença permite compartilhar, copiar, redistribuir o manuscrito em qualquer meio ou formato. Além disso, permite adaptar, remixar, transformar e construir sobre o material, desde que seja atribuído o devido crédito de autoria e publicação inicial neste periódico.

\section{DIREITOS AUTORAIS}

Os direitos autorais são mantidos pelos autores, os quais concedem à Revista REAMEC - Rede Amazônica de Educação em Ciências e Matemática - os direitos exclusivos de primeira publicação. Os autores não serão remunerados pela publicação de trabalhos neste periódico. Os autores têm autorização para assumir contratos adicionais separadamente, para distribuição não exclusiva da versão do trabalho publicada neste periódico (ex.: publicar em repositório institucional, em site pessoal, publicar uma tradução, ou como capítulo de livro), com reconhecimento de autoria e publicação inicial neste periódico. Os editores da Revista têm o direito de proceder a ajustes textuais e de adequação às normas da publicação.

\section{PUBLISHER}

Universidade Federal de Mato Grosso. Programa de Pós-graduação em Educação em Ciências e Matemática (PPGECEM) da Rede Amazônica de Educação em Ciências e Matemática (REAMEC). Publicação no Portal de Periódicos UFMT. As ideias expressadas neste artigo são de responsabilidade de seus autores, não representando, necessariamente, a opinião dos editores ou da referida universidade.

\section{EDITOR}

Patrícia Rosinke (i) 0

\section{HISTÓRICO}

Submetido: 25 de maio de 2021.

Aprovado: 16 de agosto de 2021.

Publicado: 30 de setembro de 2021. 